\title{
The Quantitative Research of Interaction between Key Parameters and the Effects on Mechanical Property in FDM
}

\author{
Hongbin Li, Taiyong Wang, and Zhiqiang Yu \\ Key Laboratory of Mechanism Theory and Equipment Design of Ministry of Education, Tianjin University, Tianjin, China \\ Correspondence should be addressed to Hongbin Li; tjlhb@tju.edu.cn
}

Received 12 June 2017; Accepted 6 September 2017; Published 20 November 2017

Academic Editor: Gianluca Percoco

Copyright ( 2017 Hongbin Li et al. This is an open access article distributed under the Creative Commons Attribution License, which permits unrestricted use, distribution, and reproduction in any medium, provided the original work is properly cited.

\begin{abstract}
The central composite design (CCD) experiment is conducted to evaluate the interaction between parameters and the effect on mechanical property. The layer thickness, deposition velocity, and air gap are considered as the key factors. Three disparate levels of the parameters are utilized in the experiment. The experimental results suggest that all these parameters can affect the bonding degree of the filaments, which affects the final tensile strength of the specimen. A new numerical model is built to describe the cooling process of the fused filament, which shows a perfect coherence with the practical temperature file of filament. It reveals what the forming mechanism of the bonding between filaments is and how these parameters act on final tensile strength of the specimen of this way from temperature. It is concluded that the parameters are not working alone; in fact they all contribute to determining the mechanical property, while the air gap plays the predominant role in determining the final tensile strength, followed by layer thickness as the next predominant factor, and the effect of deposition velocity is the weakest factor.
\end{abstract}

\section{Introduction}

Fused deposition modeling (FDM) is one of the most widely used solid freeform fabrication (SFF) systems which provide the rapid tools for the designers to generate an initial prototype from concept. A thermoplastic material is heated to a semi-molten state, extruded as an ultrathin filament, and deposited to build a part. The extrusion nozzle moves according to a toolpath defined by the part crosssectional boundary and material is deposited on top of the existing layer. When one layer is finished, the platform drops a layer height and the nozzle continues filling until the entire model is filled completely. Since mechanical properties are important for functional parts, it is absolutely essential to study the influence of various process parameters on mechanical properties so that improvement can be made through selection of best settings.

The raw form of the build material is a flexible filament that is partially melted and extruded though a heated nozzle to form a model layer on top of the previously deposited layer. The newly deposited material cools, solidifies, and bonds with the previous layer, and the eventual FDM component can be viewed as a laminate composite structure with vertically stacked layers of bonded fibers or raster [1]. The mechanical properties of FDM parts are not solely controlled by the build material of the filament but are also significantly affected by a directionally dependent production process that fabricates components with anisotropic characteristics associated with the layering [2]. Numerous process parameters (machine settings, part parameters) affect the mechanical behavior of FDM parts. It is evident that there is a need to thoroughly evaluate the effect of different parameters on mechanical properties, including raster orientation, air gap, bead width, material color, layer thickness, liquefier temperature, and deposition velocity. Fused deposition modeled parts have previously been evaluated for several different parameters, including dimensional accuracy, smoothness, compressive tensile, and flexural and impact strength [3-5]. It has been shown that material extrusion temperature slightly affects the strength and durability components produced via FDM [6]. In practice, the nozzle temperature setting should be determined according to the build material, which should be high enough to melt the material to semi-molten state, but the molecular structure of the material should not be damaged by the high temperature. Ahn et al. [6] pointed out 
that process parameters such as air gap and raster orientation significantly affected the tensile strength of FDM processed part as compared to other parameters like raster width, model temperature, and color through experimental design and analysis. In addition, built parts exhibited anisotropic properties as far as tensile strength was concerned depending on build orientation. A study made by Es-Said et al. shows that raster orientation caused alignment of polymer molecules along the direction of deposition during fabrication and tensile, flexural, and impact strength depend on orientation [7]. It is determined that the tensile strength was the greatest for parts with fibers aligned with the axis of the applied tensile force. Functional relationship between process parameters and strength (tensile, flexural, and impact) was determined using response surface methodology with experimental factors of layer thickness, build orientation, raster angle, raster width, and air gap [8]. Sood et al. [9] further examined the effect of these same five process parameters on the compressive strength of test specimens and developed a predictive equation. Their results displayed the importance of interfiber bond strength and the control of distortion during the build process. Mohamed et al. [10] presents a study on the influence of six FDM process parameters (layer thickness, air gap, raster angle, build orientation, road width, and number of contours) on the dynamic mechanical properties of the FDM manufactured parts. They stated that the most influential parameters were statistically obtained through the analysis of variance (ANOVA) technique, and the results indicate that the layer thickness and the air gap have the largest impact on dynamic mechanical properties. The air gap or infill density was also shown by Tymrak et al. [11] and Torres et al. [12] to be an important contributing factor to tensile strength, as components with higher levels of infill physically contain more material to resist deformation. The ultimate shear strength shown by Torres et al. was heavily dependent on infill as compared with the other parameters; infill makes a $56 \%$ contribution, which is nearly twice that made by the thickness and four times as influential as the heat treatment. The layer thickness was pointed out also having a strong effect on tensile performance of the compliant FDM prototype $[12,13]$ and the experimental results of previous work strongly supported this [14].

The literatures reveal that the properties of the part are sensitive to the processing parameters because parameters affect mesostructure and fiber-to-fiber bond strength. Also uneven heating and cooling cycles due to inherent nature of FDM build methodology result in stress accumulation in the built part resulting in distortion which is primarily responsible for weak bonding and thus affects the strength. It has been discovered that the parameters do not alone affect the residual stress and tensile strength in a statistically significant manner $[15,16]$. But no significant effort is made to study the interactions among the parameters. The main objective of the study is to evaluate this on mechanical behavior of parts produced by FDM. The goal of the research presented here is to further expand on such work to analyze the parameter interactions, for which there is very limited information published.
The works in the literatures show the layer thickness, air gap, deposition velocity, and raster orientation are the main factors in determining the mechanical properties. But the anisotropic behavior of tensile strength caused by raster orientation can be utilized by aligning FDM fibers along the axis of the applied stress which shows the strongest tensile strength. Besides, the default $\left(-45 /+45^{\circ}\right)$ raster orientation performs significantly better than the other rater orientation values. So the raster orientation is left without consideration of the typically altered parameters; this leaves only the layer thickness, air gap, and deposition velocity to be explored, which have been shown to be of high importance.

\section{Experimental Plan}

The design of experiments (DOE) method curtails extensive experimentation as encountered when using a full factorial experiment (FFE) [17]. The Taguchi method allows for the selection of a partial factorial test matrix to test multiple factors with several levels at once and accounts for interactions between these with a minimum amount of experiments. The Taguchi method has been shown to be a valid approach for evaluating the effects of the different factors present in FDM, simplifying experimentation, while evaluating multiple factor levels and their influence on component performance $[5,6$, 18]. To verify the effects of fabrication parameters on mechanical property and study the interaction among parameters, the DOE method is implemented. The layer thickness $(A)$, deposition velocity $(B)$, and air gap $(C)$ are treated as the factors. These three disparate levels of factors are utilized in the experiment and values of those parameters under three disparate levels are shown in Table 1. The ASTM D638 type I specimen is built to perform the test. The polylactic acid (PLA) component is utilized as the raw material. Industrial and general use of PLA is increasingly more popular due to its environmental friendliness and biocompatibility, and many desktop consumer printer models now exclusively use PLA. The extruder nozzle temperature is $220^{\circ} \mathrm{C}$ corresponding to the material temperature of $180^{\circ} \mathrm{C}$. This setting is optimized for the formation of components with the least warping and the highest strength values. Figure 1(a) shows the building direction of the specimen. Figure 1(b) shows the shape and dimensions of the test specimen. In this paper, we set the raster angle of the specimen as $\left[+45^{\circ} /-45^{\circ}\right]$. An open-source FDM printer MakerBot Z18 is adopted to build the parts. The machine can build a part with the maximum size equal to 300 $\times 305 \times 457 \mathrm{~mm}$ and with its layer resolution amounting to $100 \mu \mathrm{m}$.

The test is performed on an Instron 4468 load frame controlled by using the Bluehill Software shown in Figure 2. Load is measured with a $5 \mathrm{KN}$ load cell and strain is measured via using a 2 in gage length extensometer. Each test is conducted with setting the crosshead rate as $5 \mathrm{~mm} / \mathrm{min}$. Stress and strain calculations are performed within the Bluehill Software. Each sample set tested consists of 5 specimens for a given group of printer settings. The results of these tests are listed in Table 2.

The measurement of the bonding degree between filaments is carried out on a super depth of field microscope, 
TABLE 1: The fabrication parameters and the setting of values of the parameters under disparate levels.

\begin{tabular}{lccccc}
\hline Process parameters & Symbol & Unit & $\begin{array}{c}\text { Low } \\
\text { Level }(-1)\end{array}$ & $\begin{array}{c}\text { Middle } \\
\text { Level }(0)\end{array}$ & $\begin{array}{c}\text { High } \\
\text { Level }(+1)\end{array}$ \\
\hline Layer thickness & $A$ & $\mathrm{~mm}$ & 0.05 & 0.15 & 80 \\
Deposition velocity & $B$ & $\mathrm{~mm} / \mathrm{s}$ & 60 & 0.25 \\
Air gap & $C$ & $\mathrm{~mm}$ & 0 & 0.2 & 0.4 \\
\hline
\end{tabular}

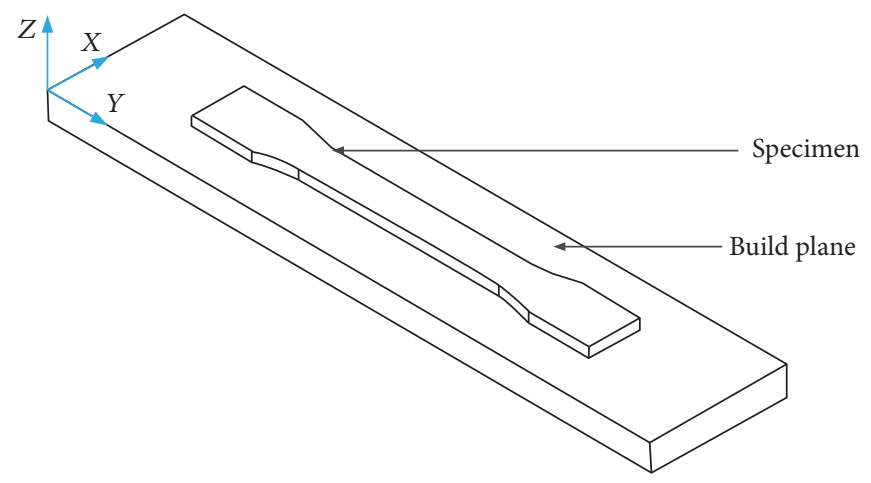

(a)

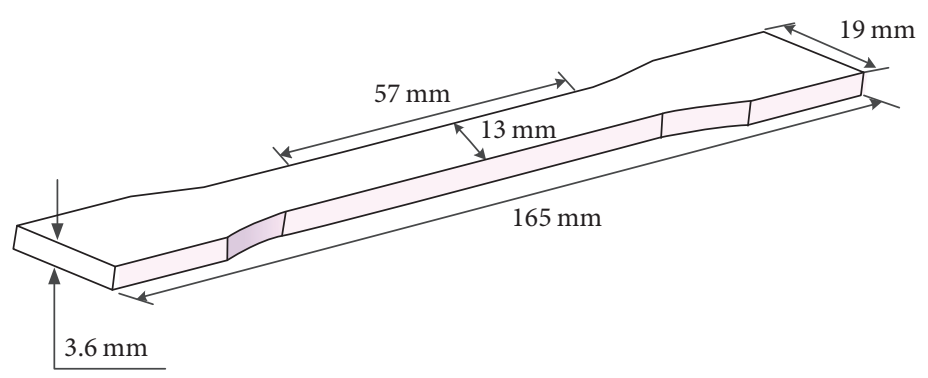

(b)

FIGURE 1: (a) Build orientation used for the fabrication of ASTM D638; (b) ASTM D638 type I specimen design and dimensions.

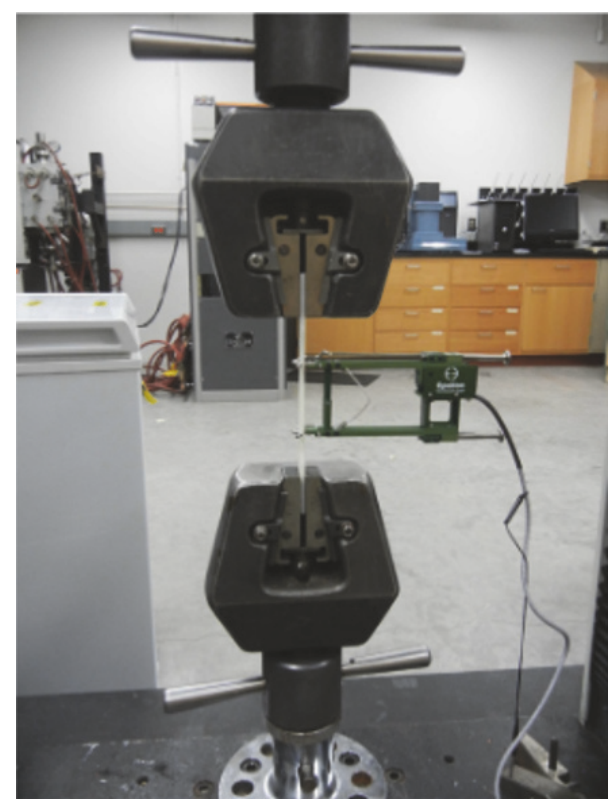

FIGURE 2: The photograph of a specimen in load frame.

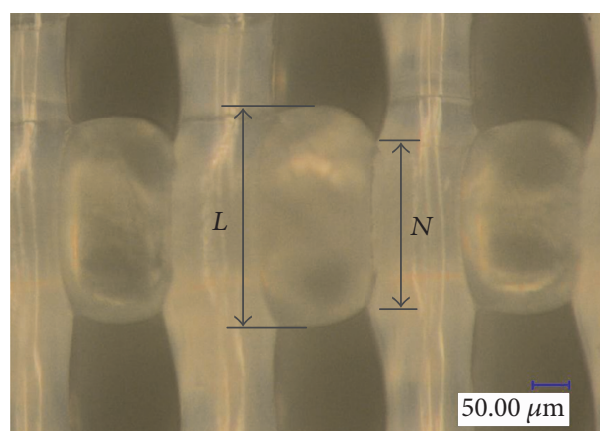

FIGURE 3: The neck length and the width of the bonding area.

shown in Figure 3. $N$ represents the neck length of the bonding area, and $L$ means the width of the filament. But the value $N$ can not represent the bonding degree between the adjacent filaments alone due to the difference of layer thickness which also can change the neck length. So the neck length rate $x=N / L$ is utilized to reflect the bonding degree ignoring the effect caused by layer thickness. The rate $x$ is also listed in Table 2. 
TABLE 2: The experiment results of tensile strength and bonding degree with various combinations of the parameters under different level values.

\begin{tabular}{|c|c|c|c|c|c|}
\hline \multirow{2}{*}{ Run order } & \multicolumn{3}{|c|}{ Factor (coded units) } & \multirow{2}{*}{$\begin{array}{c}\text { Tensile strength } \\
(\mathrm{MPa})\end{array}$} & \multirow{2}{*}{ The rate $x$} \\
\hline & $A$ & $B$ & C & & \\
\hline (1) & -1 & -1 & -1 & 30.77 & $100 \%$ \\
\hline (2) & -1 & -1 & 0 & 18.27 & $100 \%$ \\
\hline (3) & -1 & -1 & 1 & 12.50 & $100 \%$ \\
\hline (4) & -1 & 0 & -1 & 25.38 & $100 \%$ \\
\hline (5) & -1 & 0 & 0 & 13.85 & $100 \%$ \\
\hline (6) & -1 & 0 & 1 & 10.96 & $100 \%$ \\
\hline (7) & -1 & 1 & -1 & 22.31 & $100 \%$ \\
\hline (8) & -1 & 1 & 0 & 13.08 & $100 \%$ \\
\hline (9) & -1 & 1 & 1 & 9.62 & $100 \%$ \\
\hline (10) & 0 & -1 & -1 & 24.62 & $85.29 \%$ \\
\hline (11) & 0 & -1 & 0 & 17.69 & $80.90 \%$ \\
\hline (12) & 0 & -1 & 1 & 10.58 & $79.20 \%$ \\
\hline (13) & 0 & 0 & -1 & 20.19 & $81.80 \%$ \\
\hline (14) & 0 & 0 & 0 & 15.38 & $81.21 \%$ \\
\hline (15) & 0 & 0 & 1 & 8.65 & $80.79 \%$ \\
\hline (16) & 0 & 1 & -1 & 19.62 & $83.83 \%$ \\
\hline (17) & 0 & 1 & 0 & 13.08 & $81.99 \%$ \\
\hline (18) & 0 & 1 & 1 & 6.74 & $80.65 \%$ \\
\hline (19) & 1 & -1 & -1 & 15.38 & $52.27 \%$ \\
\hline (20) & 1 & -1 & 0 & 13.08 & $54.72 \%$ \\
\hline (21) & 1 & -1 & 1 & 8.27 & $59.97 \%$ \\
\hline (22) & 1 & 0 & -1 & 13.46 & $58.73 \%$ \\
\hline (23) & 1 & 0 & 0 & 11.15 & $62.23 \%$ \\
\hline$(24)$ & 1 & 0 & 1 & 7.31 & $69.30 \%$ \\
\hline$(25)$ & 1 & 1 & -1 & 11.15 & $62.47 \%$ \\
\hline (26) & 1 & 1 & 0 & 8.08 & $64.53 \%$ \\
\hline (27) & 1 & 1 & 1 & 5.96 & $66.84 \%$ \\
\hline
\end{tabular}

\section{The Experimental Results Analysis}

The results in Table 2 indicate that layer thickness, deposition velocity, and air gap in combination have a great effect on tensile behavior of the specimen. The interactions between the parameters are so apparent that they can be easily observed through the orthogonal experiment. The previous work shows that the interface mechanics involve bonding degree between adjacent filaments [14]. If the filaments have a strong bonding, the interface mechanics share the same trend; otherwise the interface mechanics are weak contradictorily. The bonding degree is severely affected by the setting of parameters in the process of fabrication. The parameters ought not to work separately, and they should have interactions with each other. Moreover, the neck length rate $x$ between filaments is the revealing of the bonding degree which is largely affected by temperature of the fabricating process.

3.1. The Interaction between Layer Thickness (A) and Deposition Velocity (B). It is noted that the parameters can affect the mechanical property on one hand; on the other hand
TABLE 3: The experiment results at different levels of layer thickness $(A)$ and velocity $(B)$.

\begin{tabular}{|c|c|c|c|}
\hline \multicolumn{2}{|c|}{ Factor } & \multirow{2}{*}{$\begin{array}{c}\text { Tensile strength } \\
(\mathrm{MPa})\end{array}$} & \multirow{2}{*}{ The rate $x$} \\
\hline$A$ & $B$ & & \\
\hline-1 & -1 & 30.77 & $100 \%$ \\
\hline-1 & 0 & 25.38 & $100 \%$ \\
\hline-1 & 1 & 22.31 & $100 \%$ \\
\hline 0 & -1 & 24.62 & $85.29 \%$ \\
\hline 0 & 0 & 20.19 & $81.80 \%$ \\
\hline 0 & 1 & 19.62 & $83.83 \%$ \\
\hline 1 & -1 & 15.38 & $52.27 \%$ \\
\hline 1 & 0 & 13.46 & $58.73 \%$ \\
\hline 1 & 1 & 11.15 & $62.47 \%$ \\
\hline
\end{tabular}

there exist interactions between parameters which also act on tensile strength as shown in Table 2.

The experiment results with different levels of layer thickness $(A)$ and velocity $(B)$ are extracted and listed in Table 3. The air gap $(C)$ stays unchanged at low level $(-1)$. When the layer thickness $(A)$ stays unchanged at low level 

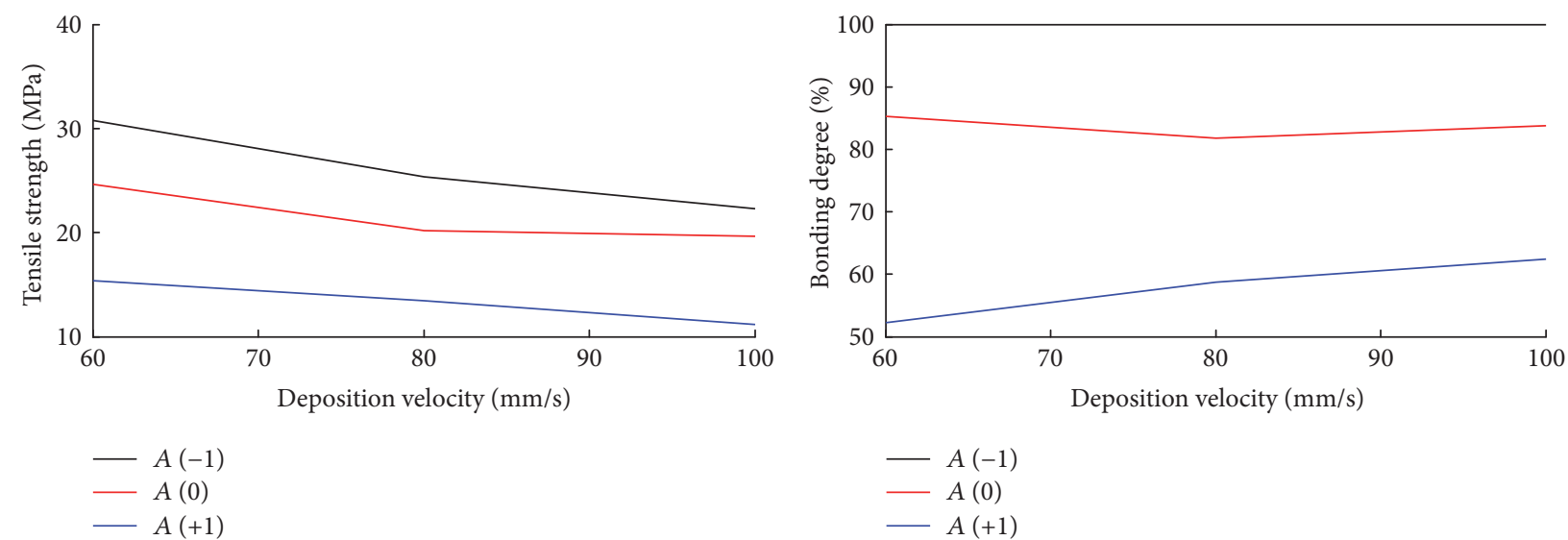

(a)



(c)

(b)

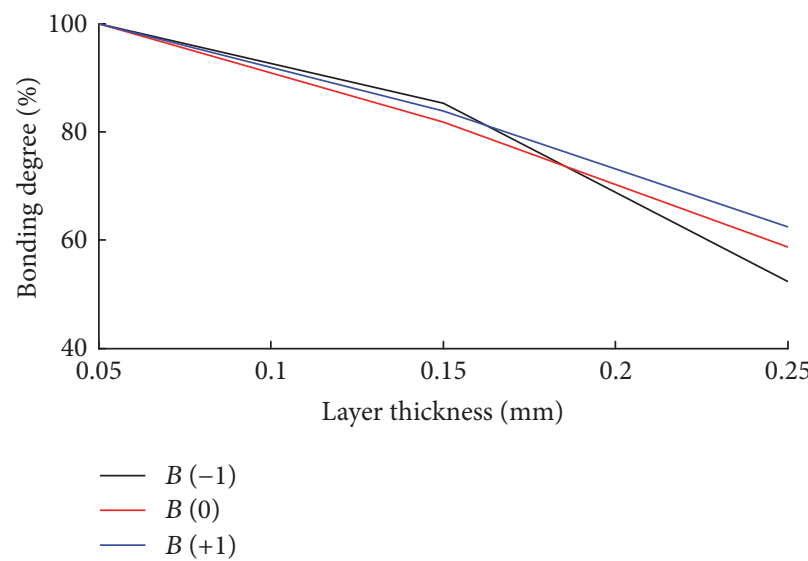

(d)

Figure 4: (a) shows the change of tensile strength with increasing of deposition velocity under different layer thickness level; (b) shows the changing of bonding degree; (c) shows the tensile strength change with the increasing of layer thickness under different level of deposition velocities; (d) shows the bonding degree change of the same situation.

$(-1)$, the tensile strength of the specimen declines from 30.77 $\mathrm{MPa}$ to $22.31 \mathrm{MPa}$ following the deposition velocity $(B)$ increasing from $60 \mathrm{~mm} / \mathrm{s}$ to $100 \mathrm{~mm} / \mathrm{s}$ with an $8.46 \mathrm{MPa}$ reduction in tensile strength. But the phenomenon in tensile strength affected by deposition velocity is not the same when the layer thickness is at middle level (0) and high level (1). At middle level (0), the tensile decreases from 24.62 MPa to 19.62 $\mathrm{MPa}$, dropping $5 \mathrm{MPa}$, and the bonding degree shares the same trend. When the layer thickness is at high level (1), the tensile strength is relatively small compared with the one that is built at low layer thickness level. Figure 4 shows the changes of tensile strength and bonding degree under different levels of deposition velocities and layer thicknesses. Figure 4 shows that the bonding degree change caused by layer thickness is much greater than deposition velocity with a maximum $47.73 \%$ decrease with layer thickness increasing from level (-1) to level (1).

It is interesting to note that when the deposition velocity increases from $60 \mathrm{~mm} / \mathrm{s}$ to $100 \mathrm{~mm} / \mathrm{s}$, the changes in tensile strength at different levels of layer thickness are apparently huge as shown in Figure 4, but the changes in neck length rate do not share the same phenomenon. The tensile strength reduces 5.39 $\mathrm{MPa}$ when the layer thickness remains low level compared with a $1.92 \mathrm{MPa}$ reduction at high level. However, the bonding degree is pretty much constant at low level of layer thickness. As observed, when the layer thickness increases from low level $(-1)$ to middle level (0), the tensile strength should decrease as analyzed before, but the opposite trend emerges in tensile strength as the deposition velocity drops from $100 \mathrm{~mm} / \mathrm{s}$ to $60 \mathrm{~mm} / \mathrm{s}$. These interesting results as listed in Table 3 are $22.31 \mathrm{MPa}$ and $24.62 \mathrm{MPa}$, respectively.

Figure 5 shows the failure models under different levels of deposition velocities and layer thicknesses and only the low level $(-1)$ of the air gap $(C)$ is considered. As shown in Figure 5(a), the cross sections of the specimens are spotless as being without any accessional broken filaments, which means the bonding between filaments is very firm and the values of bonding degree shown in Table 2 also verify this. But the conditions of the cross sections shown in Figures 5(b) and 5(c) indicate that the effect of deposition velocity becomes strong with the increasing of layer thickness.

The layer thickness $(A)$ and deposition velocity $(B)$ both can affect the heating and cooling cycles; in addition, the layer thickness also can change the amount of heat carried by the 


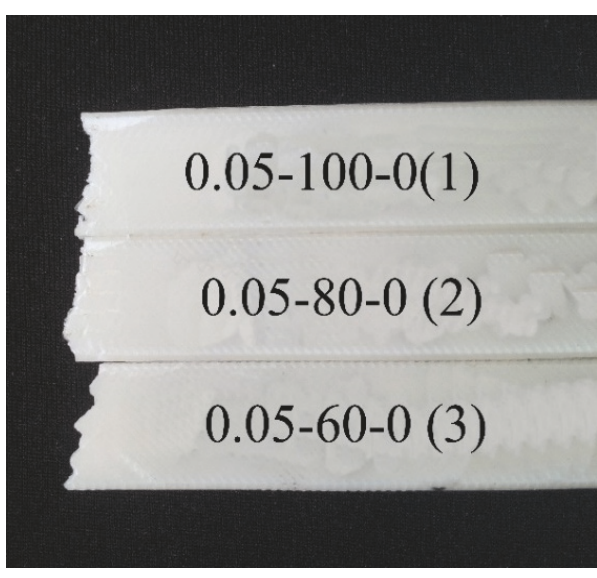

(a)

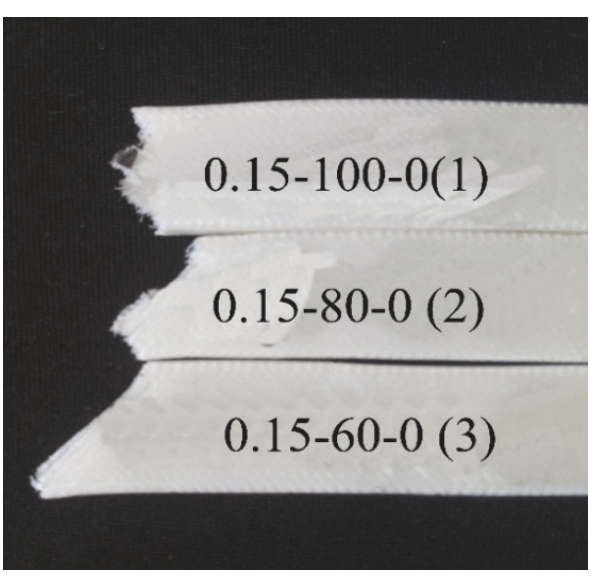

(b)

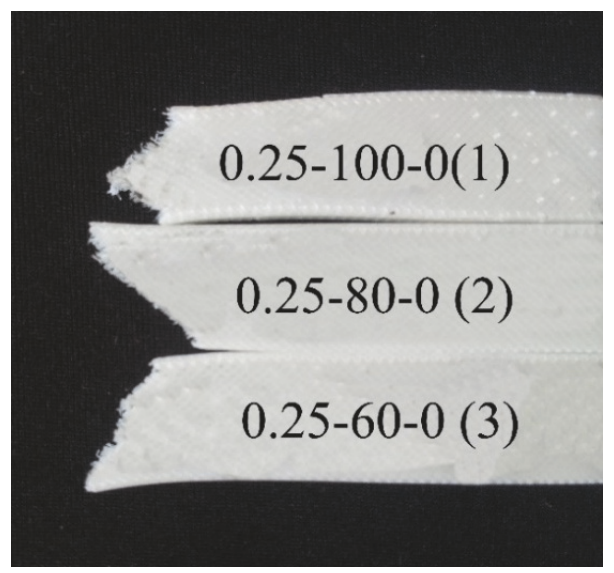

(c)

FIGURE 5: The failure models of the specimen with different building levels.

filament. Figure 5 and the value of bonding degree listed in Table 3 together indicate that the impact of layer thickness on tensile strength is stronger than deposition velocity, and the changes in bonding degree caused by layer thickness are huger than in deposition velocity and the tensile strength concurs with this phenomenon.

3.2. The Interaction between Layer Thickness (A) and Air Gap (C). The experiment results under the combined effect of layer thickness and air gap are listed in Table 4 . The deposition velocity is set as unchanged at high level and only this condition is concerned. As shown in Table 4, the tensile strength of the specimen whose air gap and layer thickness are both at low level $(-1)$ is $22.31 \mathrm{MPa}$, but the tensile strength is reduced to $9.62 \mathrm{MPa}$ when the air gap increases to high level (1), reducing 12.69 $\mathrm{MPa}$. The great variability also occurs no matter what levels the layer thicknesses are. The change in tensile strength caused by the layer thickness is obviously smaller than air gap. It can be corroborated that air gap plays the dominant role in determining the mechanical property considering the interactions of the layer thickness and the air gap. Figure 6 shows the changes of tensile strength and bonding degree caused by air gap and layer thickness.
It has been concluded that the tensile strength decreases along with the increase of layer thickness. But the opposite phenomenon occurs when the layer thickness increases from low level $(-1)$ to middle level $(0)$ and the air gap decreases from high level (1) to low level (-1); the tensile strength of the specimen increases from 9.62 $\mathrm{MPa}$ to $19.62 \mathrm{MPa}$, with an increasing of $10 \mathrm{MPa}$. But the bonding degree decreases from $100 \%$ to $83.83 \%$. When the layer thickness increases from middle level (0) to high level (1) and the air gap decreases from high level (1) to low level $(-1)$, the change in tensile strength shares the same trend with the previous case. This phenomenon states that air gap plays the dominant role in affecting the tensile strength compared with layer thickness.

Figure 7 is the cross sections of the snapped specimens. Figure 7(a) shows that the cross sections of the snapped specimens are almost the same in spite of the difference of air gap and the neck length rate shown in Table 4 is consistent with the result. The value of the bonding degree exhibits little change. Figure 7(c) shows the same trend with Figure 7(a). Only Figure 7(b) shows that the bond of the specimen built at high air gap level is weaker than the one at low level.

Figure 7 shows the layer thickness plays a more important role in determining the bonding degree than the air gap. 


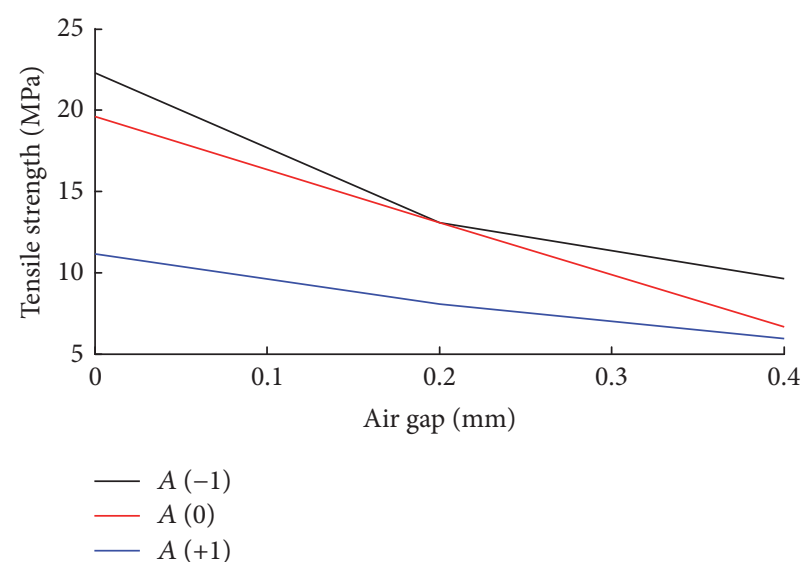

(a)

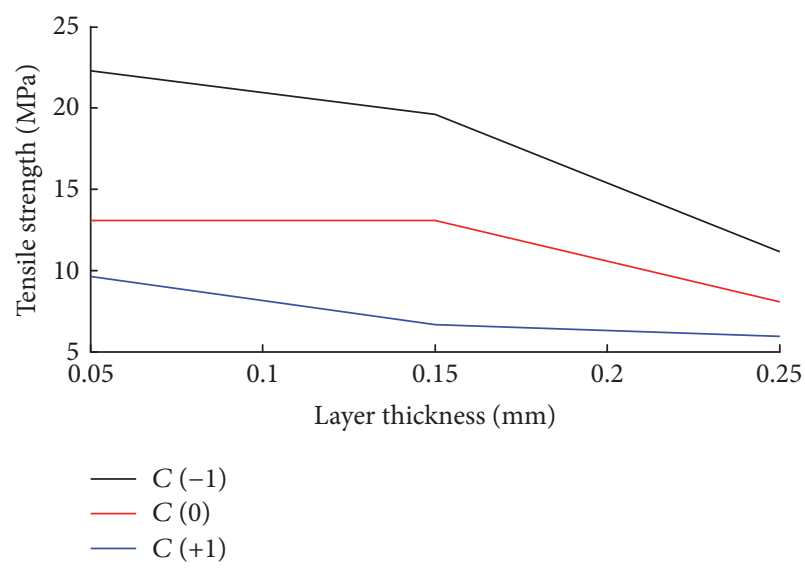

(c)

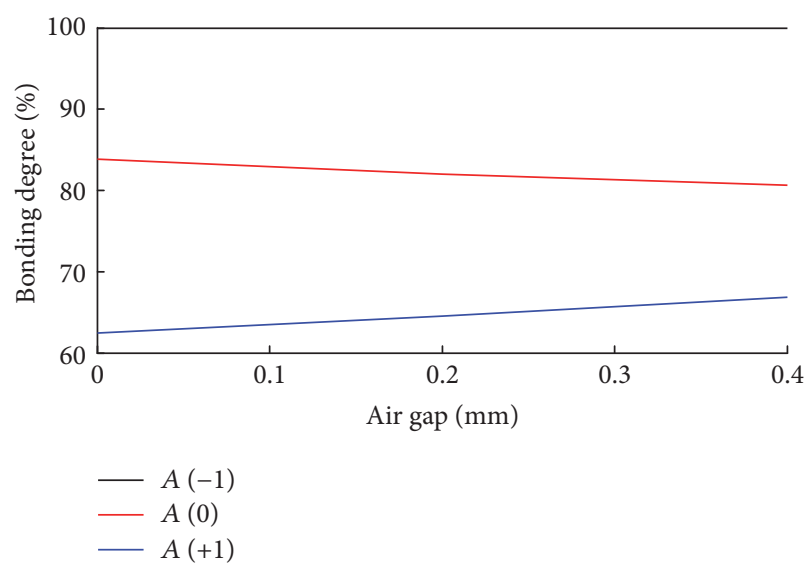

(b)

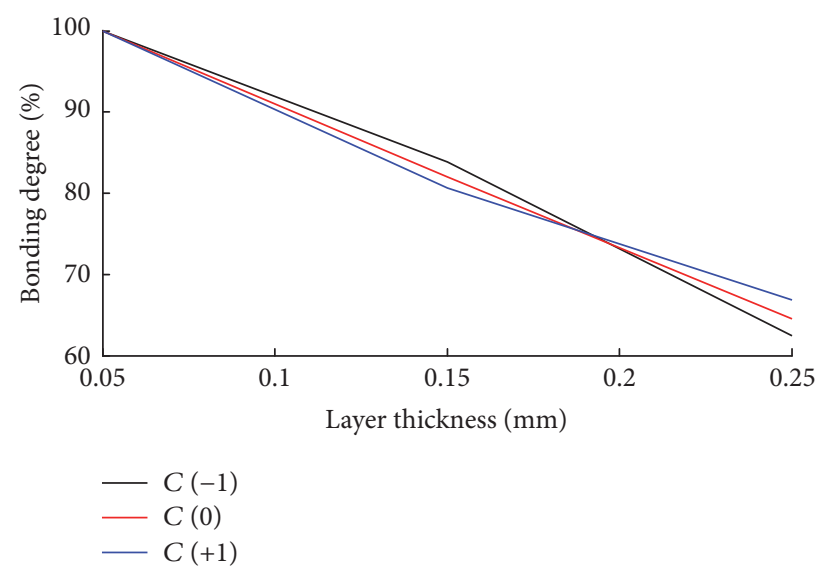

(d)

FIGURE 6: The change of tensile strength and bonding degree caused by air gap and layer thickness.

TABLE 4: The experiment results at different levels of layer thickness $(A)$ and air gap $(C)$.

\begin{tabular}{lccc}
\hline \multicolumn{2}{c}{ Factor } & Tensile strength & The rate $x$ \\
$A$ & $C$ & $(\mathrm{MPa})$ & $100 \%$ \\
\hline-1 & -1 & 22.31 & $100 \%$ \\
-1 & 0 & 13.08 & $100 \%$ \\
-1 & 1 & 9.62 & $83.83 \%$ \\
0 & -1 & 19.62 & $81.99 \%$ \\
0 & 0 & 13.08 & $80.65 \%$ \\
0 & 1 & 6.67 & $62.47 \%$ \\
1 & -1 & 11.15 & $64.53 \%$ \\
1 & 0 & 8.08 & $66.84 \%$ \\
1 & 1 & 5.96 & \\
\hline
\end{tabular}

But the change in tensile strength caused by the air gap is more prominent than the layer thickness, which means the air gap has stronger repercussions than layer thickness on mechanical property of the part.

3.3. The Interaction between Deposition Velocity (B) and Air Gap (C). The experiment results with the combined influence of deposition velocity and air gap are listed in Table 5. The middle level of the layer thickness is considered and set as unchanged. As observed, the change of tensile strength caused by deposition velocity varies a little when the deposition velocity changes from low level to high level, but with the change of air gap, a great variability occurs in tensile strength. In addition, the bonding degree varies a lot under the effect of the two parameters.

The interesting phenomenon appears when the parameter combination changes from $B(0), C(-1)$ to $B(-1), C$ (1). Under the above condition, the tensile strength decreases from 20.19 MPa to 10.58 MPa, reducing a half in the value. The results shown in Table 5 suggest that the air gap performs better than deposition velocity in affecting the mechanical property. Figure 8 shows the change of tensile strength and bonding degree under different levels of deposition velocity and air gap.

As shown in Figure 9, increasing with the air gap, the number of broken filaments becomes larger. The comparison among the figures shows that the deposition velocity also can affect the bonding degree of the filaments. The count of broken filaments which remained at the cross section has the same changing trend of the neck length rate shown in Table 5. 


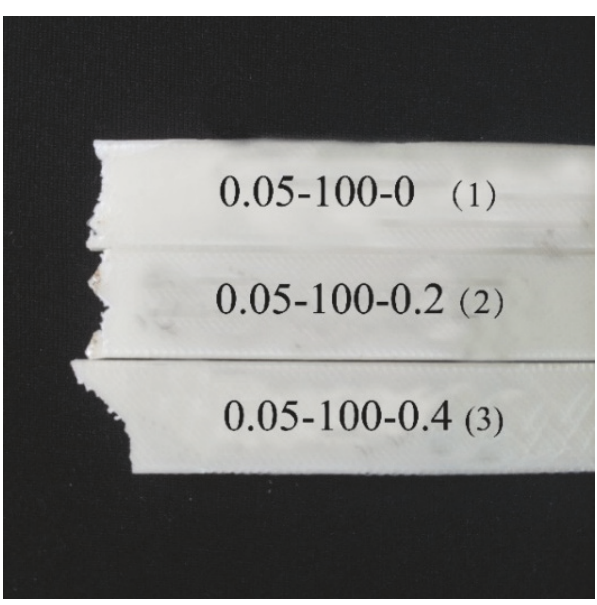

(a)

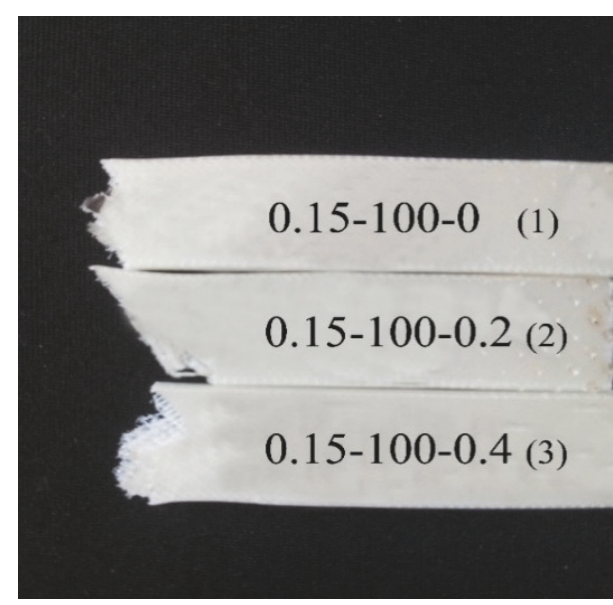

(b)

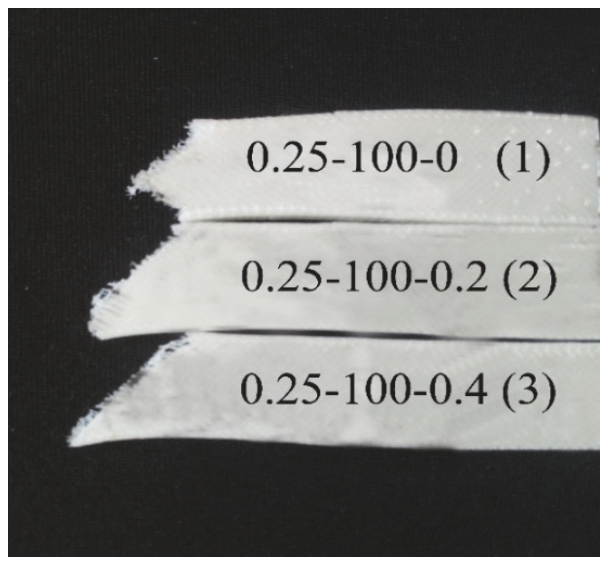

(c)

FIGURE 7: The failure specimen at different building levels of layer thickness and air gap.

The comparison between the figures, especially between Figures 9(a) and 9(b), indicates that the deposition velocity affects the bond of the filament more significantly than the air gap. But the reinforcement of the tensile strength aroused by the deposition velocity is too small compared with the weakening caused by the air gap.

It indicates that the air gap takes up the dominant position in affecting the final property of the part considering the interaction of deposition velocity and air gap.

\section{Discussion}

The specimen is composed of stacked layers of bonded fibers, and the quality of the bonding plays a significant role in determining the tensile strength. It had been experimentally demonstrated that bond quality between adjacent filaments depended on envelope temperature and variations in the convective conditions within the building part while testing flexural strength specimen $[19,20]$.

The experiment results shown in part 3 indicate the parameters (layer thickness, deposition velocity, and air gap) do influence the tensile strength and the interactions among the parameters on boning degree of the filaments are significant. While there is little literature revealing what the forming mechanism of the bonding between filaments is and how these parameters act on tensile strength of the specimen, in this paper, the workings of this way from temperature will be explained.

According to the basic principle of diffusion welding [21], the number of molecular diffusion crossing the interface of adjacent filaments can be represented as

$$
d m=D_{0} e^{-Q / R T} \frac{d C}{d x} d t
$$

where $D_{0}$ and $Q$ are diffusion coefficient and activation energy of the material, respectively. $R$ is ideal gas constant. $T$ and $C$ represent the interface temperature and density.

As shown in formula (1), the number of molecular diffusion is proportional to temperature $T$. The bonding strength coefficient of interface based on thermostat welding is shown as follows [22]:

$$
\alpha=\frac{\sigma_{i}}{\sigma_{f}}=\left[\int_{0}^{t} K^{4}\left(T_{i}(t)\right) d t\right]^{1 / 4} .
$$




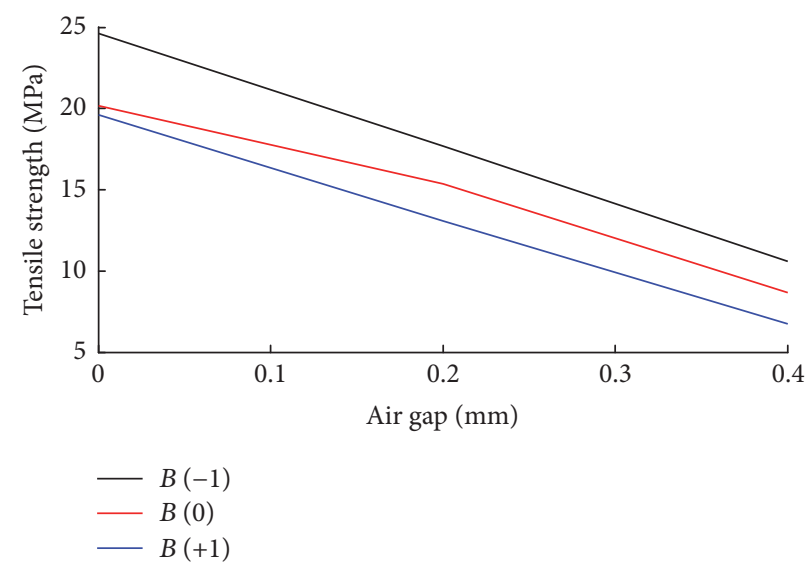

(a)

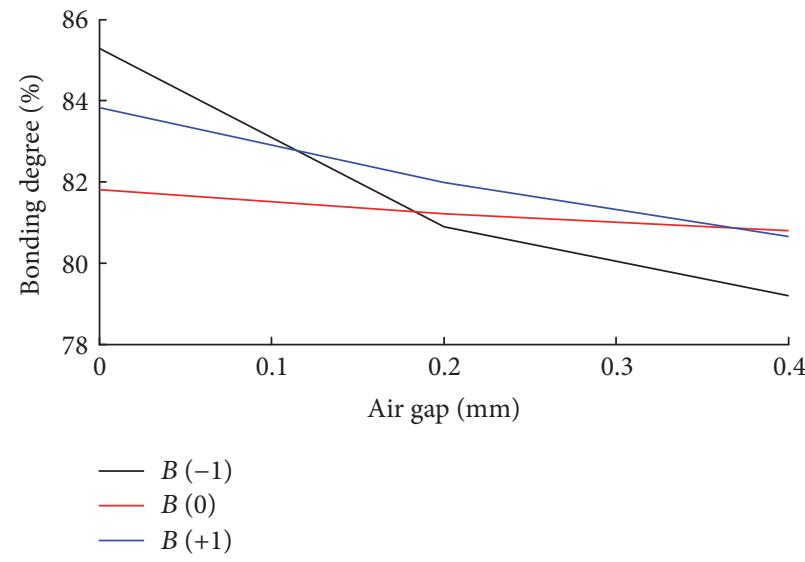

(c)

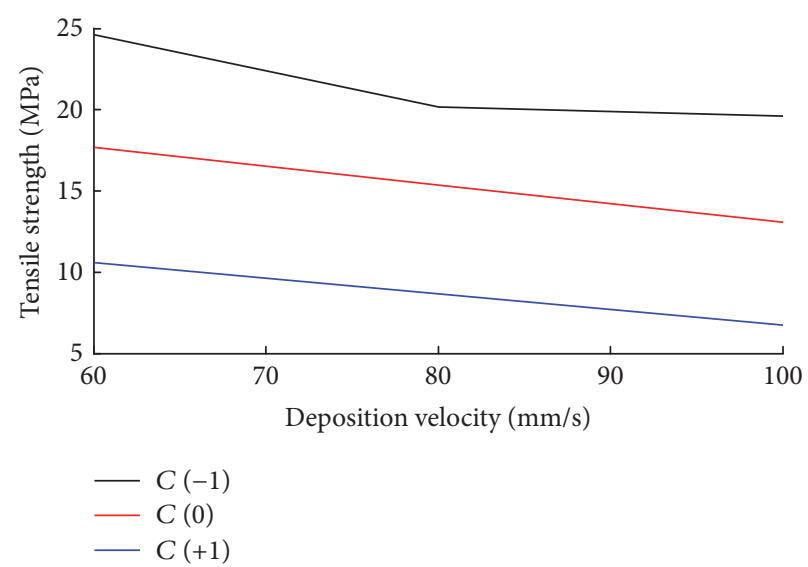

(b)

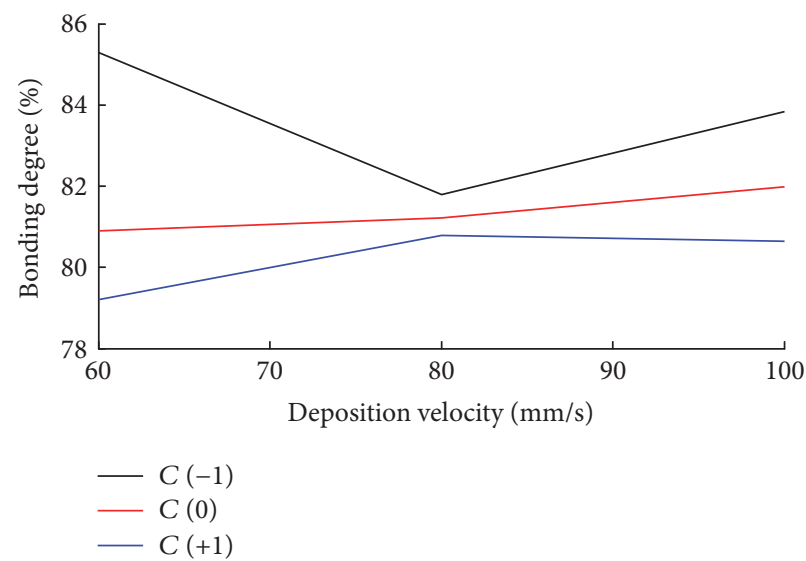

(d)

Figure 8: The change of tensile strength and bonding degree with different deposition velocities and air gaps.

The terms $\sigma_{i}$ and $\sigma_{f}$ represent the interface bonding strength and tensile strength of the material, respectively. $K\left(T_{i}\right)$ is coefficient of thermal bonding, which can be represented as

$$
K\left(T_{i}\right)= \begin{cases}A\left(T_{c}\right) \exp \left[\frac{Q}{R}\left(\frac{1}{T_{c}}-\frac{1}{T_{i}}\right)\right] & T_{i}>T_{c} \\ 0 & T_{i}<T_{c},\end{cases}
$$

where $A\left(T_{c}\right)$ represents the fusion rate of the interface under critical bonding degree and the terms $T_{c}$ and $T_{\mathrm{g}}$ are the glass transition temperature and practical temperature of interface when the bonding is proceeding.

So, the bonding strength of interface can be obtained as follows:

$$
\sigma_{i}=K \cdot\left[\int_{0}^{1} \zeta\left(T_{i}\right) \cdot e^{-k / T_{i}(t)} d t\right]^{1 / 4}
$$

with

$$
\zeta\left(T_{i}\right)= \begin{cases}1 & T_{i}>T_{\mathcal{c}} \\ 0 & T_{i}<T_{\mathcal{c}}\end{cases}
$$

where $K=\sigma_{f} \cdot A\left(T_{c}\right) \cdot e^{m} ; m=Q / T_{c} ; k=4 Q / R$.
Formula (4) shows that the filament with high temperature can form a strong bond and the temperature of the filament is closely relevant to fabrication parameters.

Li et al. [23] used the lumped capacity (LC) analysis for modeling the cooling process of the extruded filament. The analytical solution proposed by $\mathrm{Li}$ et al. is shown as follows:

$$
T=T_{E}+\left(T_{L}-T_{E}\right) e^{-m x},
$$

with

$$
\begin{aligned}
& m=\frac{(\sqrt{1+4 \alpha \beta}-1)}{2 \alpha}, \\
& x=v t
\end{aligned}
$$

where

$$
\begin{aligned}
& \alpha=\frac{k}{\rho C v}, \\
& \beta=\frac{h P}{\rho C A v} .
\end{aligned}
$$

The terms $A, P$, and $v$ represent the cross-sectional area of the filament, the perimeter of the filament, and its deposition 


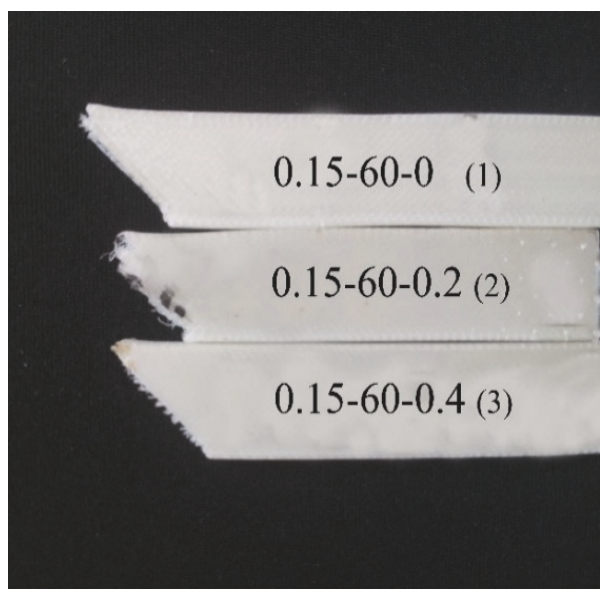

(a)



(b)

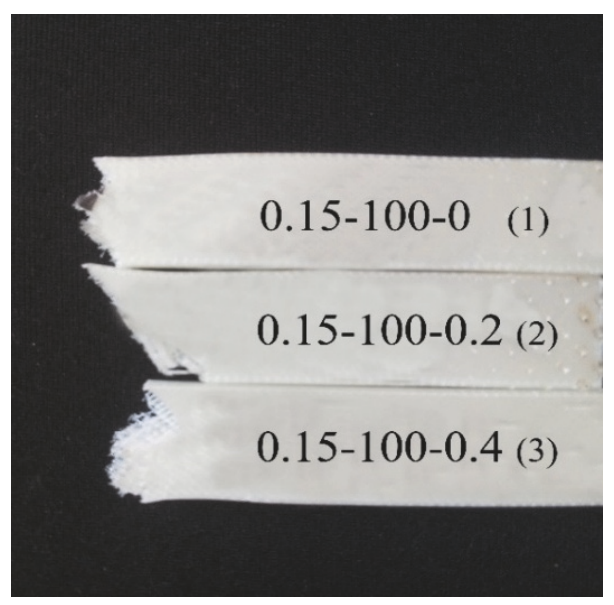

(c)

FIgURE 9: The failure specimen at different building levels of deposition velocity and air gap.

velocity, respectively. But the heat transfer between filament and air is mainly considered in this analytical model, neglecting heat transition between filament and platform or among the filaments. A new numerical model for the cooling process of the fused filament is built based on some assumptions, considering the practical situation, as follows:

(1) The contract area between the depositing filament and the platform or the deposited one takes up onefourth of the filament.

(2) The bare area of the depositing filament in air accounts for 50 percent of the filament.

(3) The temperature value of the air which is very close to the deposited filament is almost the same with the deposited one.

According to the above assumptions, a new analytical model can be achieved as follows:

$$
\begin{aligned}
T_{n+1}= & T_{n}+\frac{1}{2} \cdot\left(T_{L}-T_{E}\right) e^{-m_{1} x}+\frac{1}{4}\left(T_{L}-T_{n}\right) e^{-m_{1} x} \\
& +\frac{1}{4}\left(T_{L}-T_{0}\right) e^{-m_{2} x}
\end{aligned}
$$

with

$$
\begin{aligned}
& m_{1}=\frac{\left(\sqrt{1+4 \alpha \beta_{1}}-1\right)}{2 \alpha}, \\
& m_{2}=\frac{\left(\sqrt{1+4 \alpha \beta_{2}}-1\right)}{2 \alpha},
\end{aligned}
$$

where

$$
\begin{aligned}
& \beta_{1}=\frac{h_{1} P}{\rho C A v_{x}}, \\
& \beta_{2}=\frac{h_{2} P}{\rho C A v_{x}} .
\end{aligned}
$$

The terms $T_{n+1}$ and $T_{n}$ represent the temperature of the $n+1$ th and the $n$th layers. $T_{L}, T_{E}$, and $T_{0}$ are the temperature values of nozzle, air, and platform, respectively.

Experimental measurements performed on filaments deposited on the base platform are used to assess the validity of the new model described above. The temperature sensor is fixed on the platform to collect data, shown in Figure 10. 


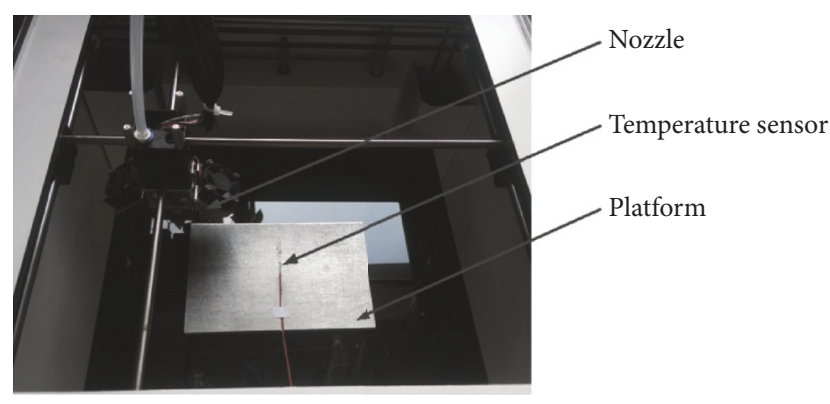

FIGURE 10: The temperature-measuring device.

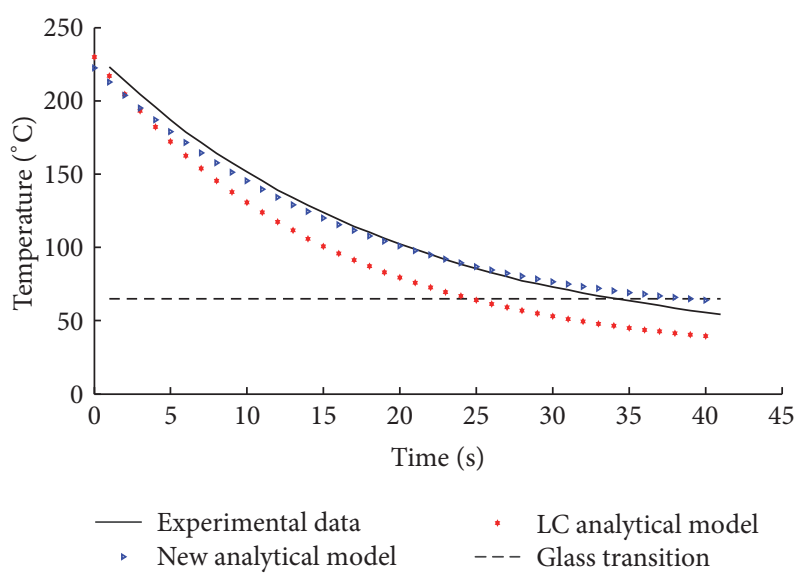

FIGURE 11: Experimental profiles compared with analytical models.

Figure 11 shows a comparison between the theoretical model and experimental data collected for the cooling process of a single deposited filament. The measured data, in spite of the measurement limitations, in general agrees more with the new model compared with the LC analytical model, which means the new numerical model shown in formula (9) describes the cooling process of the filament better. But in practice, the temperature of the filament as it leaves the tip and deposits onto the platform is found to range from $120^{\circ} \mathrm{C}$ to $140^{\circ} \mathrm{C}$, which is significantly lower than that specified for the liquefier $\left(220^{\circ} \mathrm{C}\right)$. The interface temperature rises above the glass transition temperature $\left(T_{g}\right)$ immediately upon extrusion of the filament and stays above $T_{g}$ only for a little time, shown in Figure 11, which has a significant effect on bonding of the filaments. And the cooling process is influenced by the parameters heavily.

For better understanding the mechanism of the parameters acting on filament bonding, the temperature data is collected with different parameter values. The thermocouple is positioned in the center of the square cross-sectional area of the specimen to collect the first eight layers which is shown in Figure 10.

4.1. The Effect of Layer Thickness and Deposition Velocity on Bonding Degree and Tensile Strength. The temperature files obtained show that the temperature of the filament on the bottom layer periodically rises above the glass transition temperature with the deposition of each additional layer to the specimen. Each peak is followed by a rapid decrease in the temperature. The temperature files, shown in Figure 12, indicates that the filament remains above the glass transition temperature during a significant portion of the fabrication process. This confirms the importance of heat transfer through conduction within the structure with the deposition of the filament. The comparison of the temperature files in the three layer thickness values shown in Figure 12 shows that the bottom layer can obtain more heat with layer thickness increasing but the neck length rate $x$ shown in Table 3 does not cater to this. This can be explained by the fact that the thin layer needs less heat to bond with the adjacent filament. But the comparison in Figure 12 also indicates that more heat can be transferred to the bottom with a smaller deposition speed and the time of the filament staying above the glass transition temperature is longer with a smaller velocity, which is suggested by formula (4) that the filament can obtain a strong bond. It is interesting to note that the degree of interaction between the two parameters is different. Figure 12(a) shows the deposition velocity has little impact on heat transition when the layer thickness is at low level setting. But the effect of deposition velocity is obviously different with different values when the layer thickness is at middle and high level settings.

This phenomenon is strongly supported by Figure 4 and the neck length rate listed in Table 3, which means that the degree of interaction between the two parameters heavily depends on the values of the two parameters.

The new analytical model of the cool process shown in formula (9) also notes that more heat will be lost with a high deposition speed. Experiments and model predictions suggest that layer thickness has a greater effect on bonding strength than deposition velocity, but the bonding between filaments is influenced by the two factors.

\subsection{The Effect of Layer Thickness and Air Gap on Bonding} Degree and Tensile Strength. The temperature files shown in Figure 13 show that, compared with layer thickness, air gap has less effect on heat transition within the structure. It is interesting to note that the bottom obtains more heat and the time above the glass transition is longer with a smaller air gap value and the tensile strength and neck length rate listed in Table 4 share the same trend. The comparison among temperature files shown in Figure 13 signifies that the effect of air gap on heat transition tends to intensify with layer thickness increase, which is supported by the number of residual filaments remained on the section shown in Figure 7. This phenomenon indicates that heat transition caused by air gap is also affected by layer thickness.

The tensile strength of the specimen described in Table 4 shows that the air gap plays the dominant role in affecting the tensile strength of the filament, but Figure 7 combines with Figure 13 together to show that the layer thickness has a greater effect in promoting the bonding, which also can strengthen the tensile strength of the specimen supported by the tensile value shown in Table 4 . 




(a)

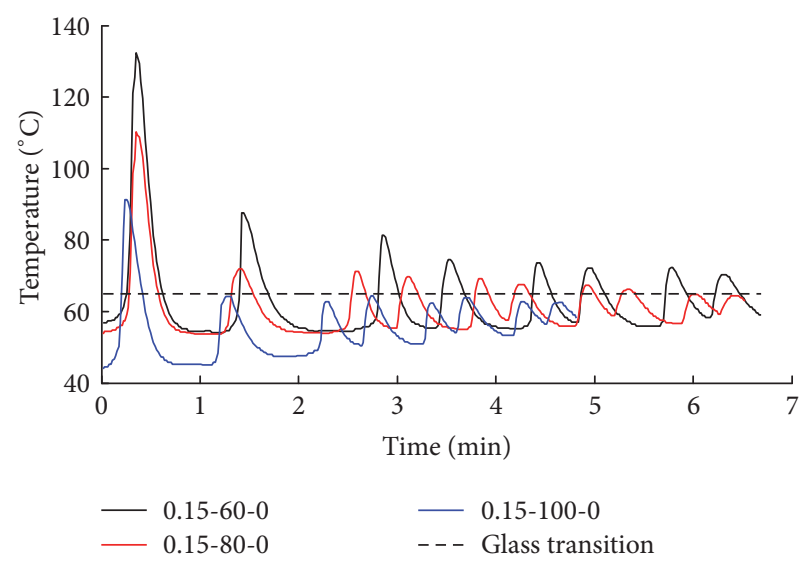

(b)

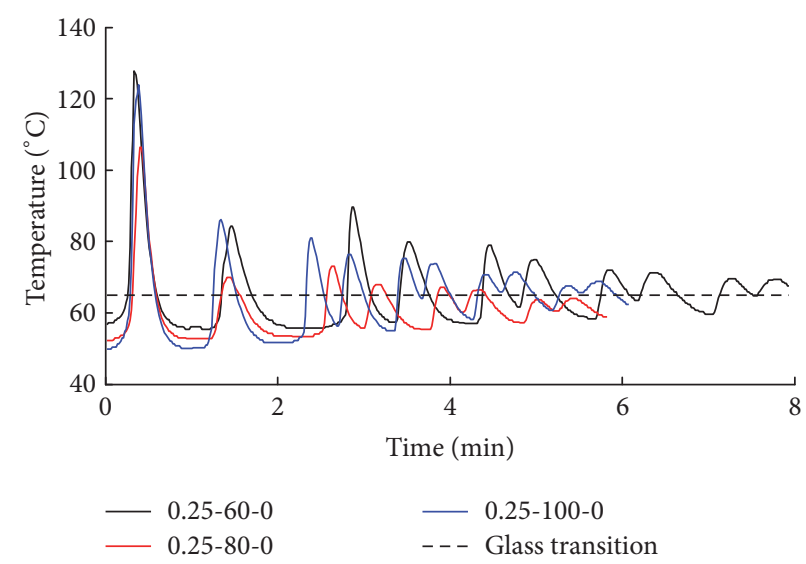

(c)

FIGURE 12: The temperature files under different levels of layer thickness and deposition velocity.

4.3. The Effect of Deposition Velocity and Air Gap on Tensile Strength. Figure 14(a) shows that the effect of air gap on heat transition within the structure is much more obvious at a smaller deposition velocity, but the effect tends to be weak with deposition velocity increase as shown in Figures 14(b) and 14(c). The neck length rate change listed in Table 5 shares a similar trend. The situation of the cross sections shown in Figure 9 bears this out. But the air gap does not have as obvious an impact on bonding degree compared with deposition velocity. But the tensile strength change caused by air gap is more apparent than deposition velocity.

The air gap and deposition velocity both can affect bonding degree of the specimen, and the role of the deposition velocity is greater than air gap. The effect of air gap on deposition velocity acting on bonding degree gradually grows less with deposition velocity increasing. The bonding degree change caused by deposition velocity in each case shown in Figure 8 interprets this better. But the tensile strength change caused by air gap and deposition velocity suggests that the air gap is still the chief role.

\section{The Conclusion}

The layer thickness $(A)$, deposition velocity $(B)$, and air gap $(C)$ are considered as the key factors to conduct the central composite design experiment to evaluate the interactions of the parameters.

A new numerical model is built to describe the cooling process of the fused filament and the practical temperature files of filament show a perfect coherence with the new model compared with the LC analytical model, which means the new numerical model describes the cooling process of the filament better. It reveals what the forming mechanism of the bonding between filaments is and how these parameters act on final tensile strength of the specimen of this way from temperature in this paper. The analysis shows that the layer thickness and deposition velocity have a greater effect than air on heat transition which can promote the bonding process of filaments. The air gap also affects the heat transition, but its dominant role is changing the effective area of the specimen which would finally affect the tensile strength.

The interactions between the parameters are studied and the reasons behind the observed response can be summarized as follows.

(1) The layer thickness $(A)$, deposition velocity $(B)$, and air gap $(C)$ can affect the heat transition within the structure. The heat transition between filaments can strengthen the bonding which will reinforce the tensile strength of the part. The layer thickness plays 


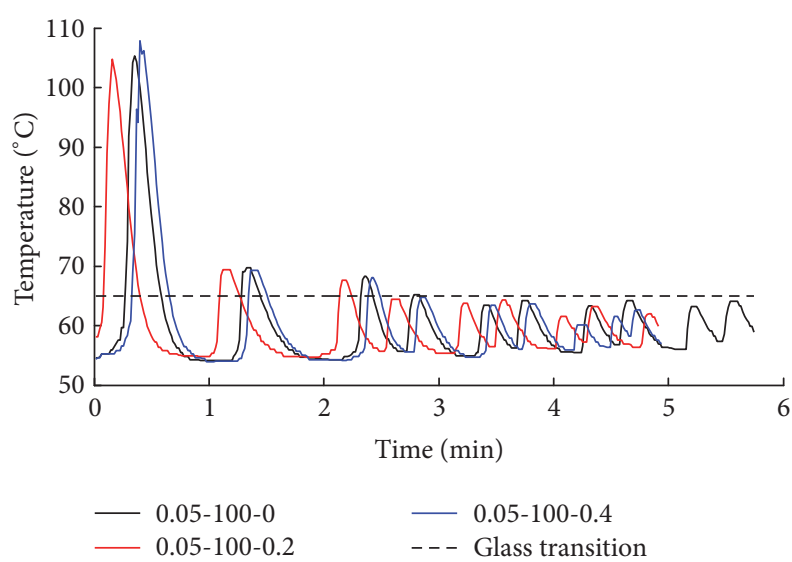

(a)

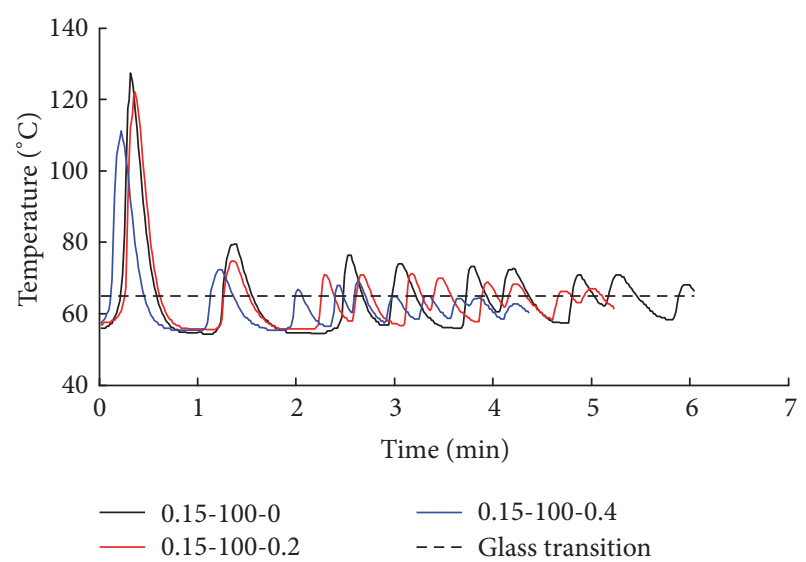

(b)

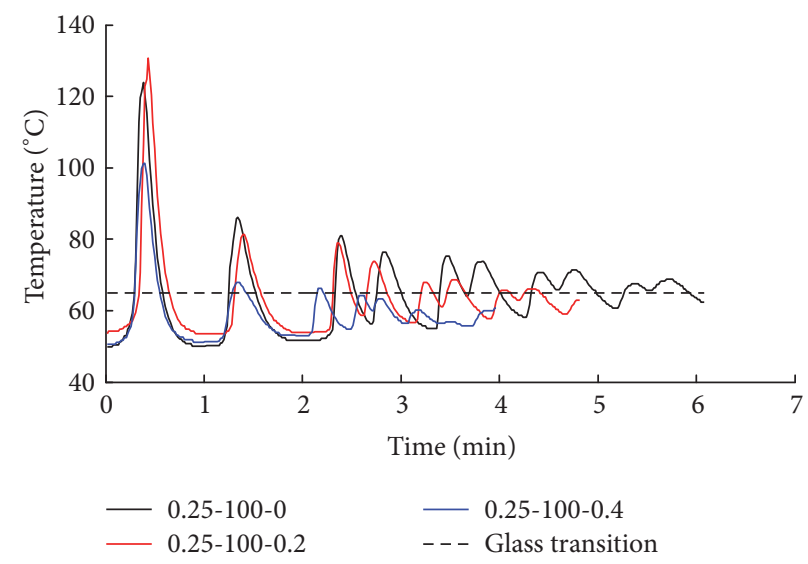

(c)

Figure 13: The temperature files under different levels of layer thickness and air gap.

TABLE 5: The experiment results with the combined influence of deposition velocity and air gap.

\begin{tabular}{lccc}
\hline & Factor & & Tensile strength \\
$B$ & $C$ & 24.62 & The rate $x$ \\
\hline-1 & -1 & 17.69 & $85.29 \%$ \\
-1 & 0 & 10.58 & $80.90 \%$ \\
-1 & 1 & 20.19 & $79.20 \%$ \\
0 & -1 & 15.38 & $81.80 \%$ \\
0 & 0 & 8.65 & $81.21 \%$ \\
0 & 1 & 19.62 & $80.79 \%$ \\
1 & -1 & 13.08 & $83.83 \%$ \\
1 & 0 & 6.74 & $81.99 \%$ \\
1 & 1 & & $80.65 \%$ \\
\hline
\end{tabular}

the most significant role in affecting the conformation of the bonding, followed by deposition velocity as the second significant and the effect of air gap is the least significant.

(2) The air gap also can change the force bearing area of the part and the effect of this change on mechanical property is more apparent than the work of bonding between filaments. It means that the air gap plays a dominant role in determining the tensile strength, followed by layer thickness.

The experiments and the new analytical model suggest that a small value of air gap and layer thickness are preferred if a high tensile strength specimen is needed and the deposition velocity can be set comparatively bigger to achieve high fabrication efficiency. A specimen with a big value of air gap, a small layer thickness, and deposition velocity may share 


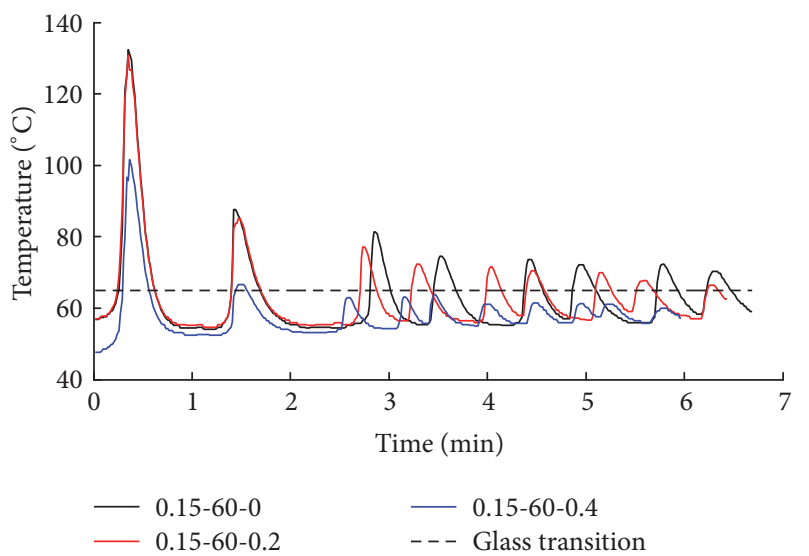

(a)

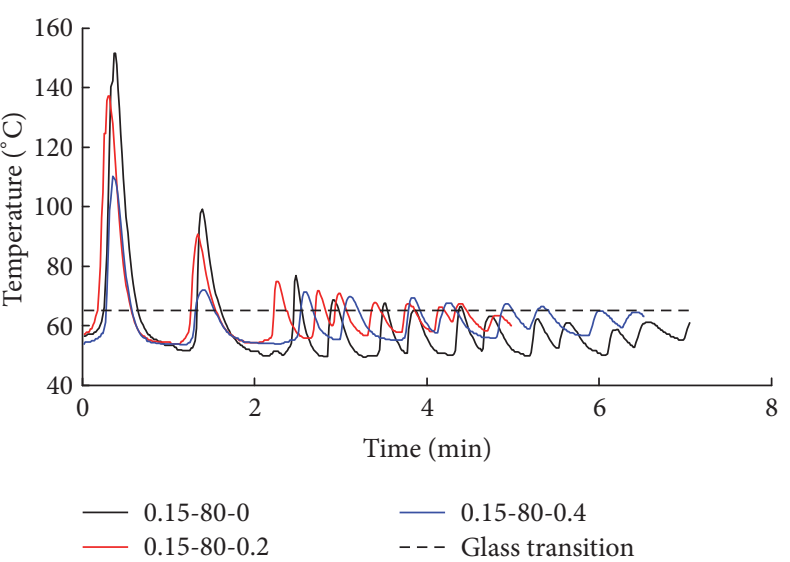

(b)

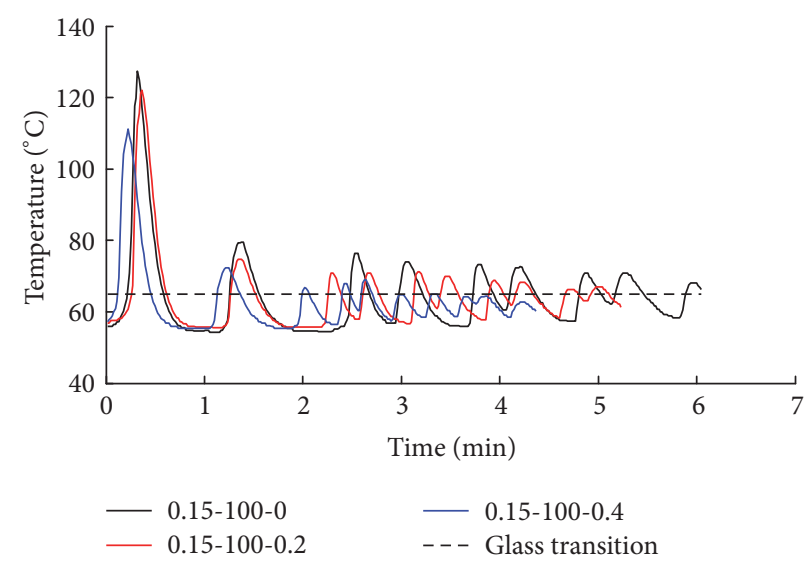

(c)

FIGURE 14: The temperature files under different levels of deposition velocity and air gap.

the same tensile strength with the one which is under the opposite parameters setting.

\section{Conflicts of Interest}

The authors declare that there are no conflicts of interest regarding the publication of this paper.

\section{Acknowledgments}

This research was sponsored by the National Natural Science Foundation of China under Grant 51475324.

\section{References}

[1] A. K. Sood, R. K. Ohdar, and S. S. Mahapatra, "Experimental investigation and empirical modelling of FDM process for compressive strength improvement," Journal of Advanced Research, vol. 3, no. 1, pp. 81-90, 2012.

[2] C. W. Ziemian, M. M. Sharma, and S. N. Ziemian, "Anisotropic mechanical properties of ABS parts fabricated by fused deposition modelling," in Mechanical Engineering, M. Gokcek, Ed., pp. 159-180, 2012.
[3] C. S. Lee, S. G. Kim, H. J. Kim, and S. H. Ahn, "Measurement of anisotropic compressive strength of rapid prototyping parts," Journal of Materials Processing Technology, vol. 187-188, pp. 627630, 2007.

[4] S. K. Panda, S. Padhee, A. K. Sood, and S. S. Mahapatra, "Optimization of Fused Deposition Modelling (FDM) Process Parameters Using Bacterial Foraging Technique," Intelligent Information Management, vol. 1, no. 2, pp. 89-97, 2009.

[5] J. Zhang and A. Peng, "Process-parameter optimization for fused deposition modeling based on Taguchi method," Advanced Materials Research, vol. 538-541, pp. 444-447, 2012.

[6] S.-H. Ahn, M. Montero, D. Odell, S. Roundy, and P. K. Wright, "Anisotropic material properties of fused deposition modeling ABS," Rapid Prototyping Journal, vol. 8, no. 4, pp. 248-257, 2002.

[7] O. S. Es-Said, J. Foyos, R. Noorani, M. Mendelson, R. Marloth, and B. A. Pregger, "Effect of layer orientation on mechanical properties of rapid prototyped samples," Materials and Manufacturing Processes, vol. 15, no. 1, pp. 107-122, 2000.

[8] A. K. Sood, R. K. Ohdar, and S. S. Mahapatra, "Parametric appraisal of mechanical property of fused deposition modelling processed parts," Materials and Design, vol. 31, no. 1, pp. 287295, 2010.

[9] A. K. Sood, V. Chaturvedi, S. Datta, and S. S. Mahapatra, "Optimization of process parameters in fused deposition modeling using weighted principal component analysis," Journal of 
Advanced Manufacturing Systems, vol. 10, no. 2, pp. 241-259, 2011.

[10] O. A. Mohamed, S. H. Masood, J. L. Bhowmik, M. Nikzad, and J. Azadmanjiri, "Effect of Process Parameters on Dynamic Mechanical Performance of FDM PC/ABS Printed Parts Through Design of Experiment," Journal of Materials Engineering and Performance, vol. 25, no. 7, pp. 2922-2935, 2016.

[11] B. M. Tymrak, M. Kreiger, and J. M. Pearce, "Mechanical properties of components fabricated with open-source 3-D printers under realistic environmental conditions," Materials and Design, vol. 58, pp. 242-246, 2014.

[12] J. Torres, J. Cotelo, J. Karl, and A. P. Gordon, "Mechanical property optimization of FDM PLA in shear with multiple objectives," JOM, vol. 67, no. 5, pp. 1183-1193, 2015.

[13] Z. A. Khan, B. H. Lee, and J. Abdullah, "Optimization of rapid prototyping parameters for production of flexible ABS object," Journal of Materials Processing Technology, vol. 169, no. 1, pp. 5461, 2005.

[14] H. Li, T. Wang, J. Sun, and Z. Yu, "The adaptive slicing algorithm and its impact on the mechanical property and surface roughness of freeform extrusion parts," Virtual and Physical Prototyping, vol. 11, no. 1, pp. 27-39, 2016.

[15] Y. Zhang and K. Chou, "A parametric study of part distortions in fused deposition modelling using three-dimensional finite element analysis," Proceedings of the Institution of Mechanical Engineers, Part B: Journal of Engineering Manufacture, vol. 222, no. 8, pp. 959-967, 2008.

[16] J. Torres, M. Cole, A. Owji, Z. DeMastry, and A. P. Gordon, "An approach for mechanical property optimization of fused deposition modeling with polylactic acid via design of experiments," Rapid Prototyping Journal, vol. 22, no. 2, pp. 387-404, 2016.

[17] R. K. Roy, "Design of experiments using the Taguchi approach," in 16 Steps to Product and Process Improvement, John Wiley and Sons, New York, NY, USA, 2001.

[18] J. P. Patel, C. P. Patel, and U. J. Patel, "A review on various approach for process parameter optimization of fused deposition modeling (FDM) process and Taguchi approach for optimization," vol. 2, pp. 361-365, 2012.

[19] Q. Sun, G. M. Rizvi, C. T. Bellehumeur, and P. Gu, "Effect of processing conditions on the bonding quality of FDM polymer filaments," Rapid Prototyping Journal, vol. 14, no. 2, pp. 72-80, 2008.

[20] P. K. Gurrala and S. P. Regalla, "Part strength evolution with bonding between filaments in fused deposition modelling: this paper studies how coalescence of filaments contributes to the strength of final FDM part," Virtual and Physical Prototyping, vol. 9, no. 3, pp. 141-149, 2014.

[21] H'Kekakef, The diffusion welding of the material [M.S. thesis], He Kangsheng translation, National Defense of Industry Press, Beijing, China, 1982.

[22] R. P. Wool, B.-L. Yuan, and O. J. McGarel, "Welding of polymer interfaces," Polymer Engineering and Science, vol. 29, no. 19, pp. 1340-1367, 1989.

[23] L. Li, P. Gu, Q. Sun, and C. Bellehumenu, "Modeling of bond formation in FDM process," The Transactions of NAMRI/SME, vol. 31, pp. 613-632, 2003. 

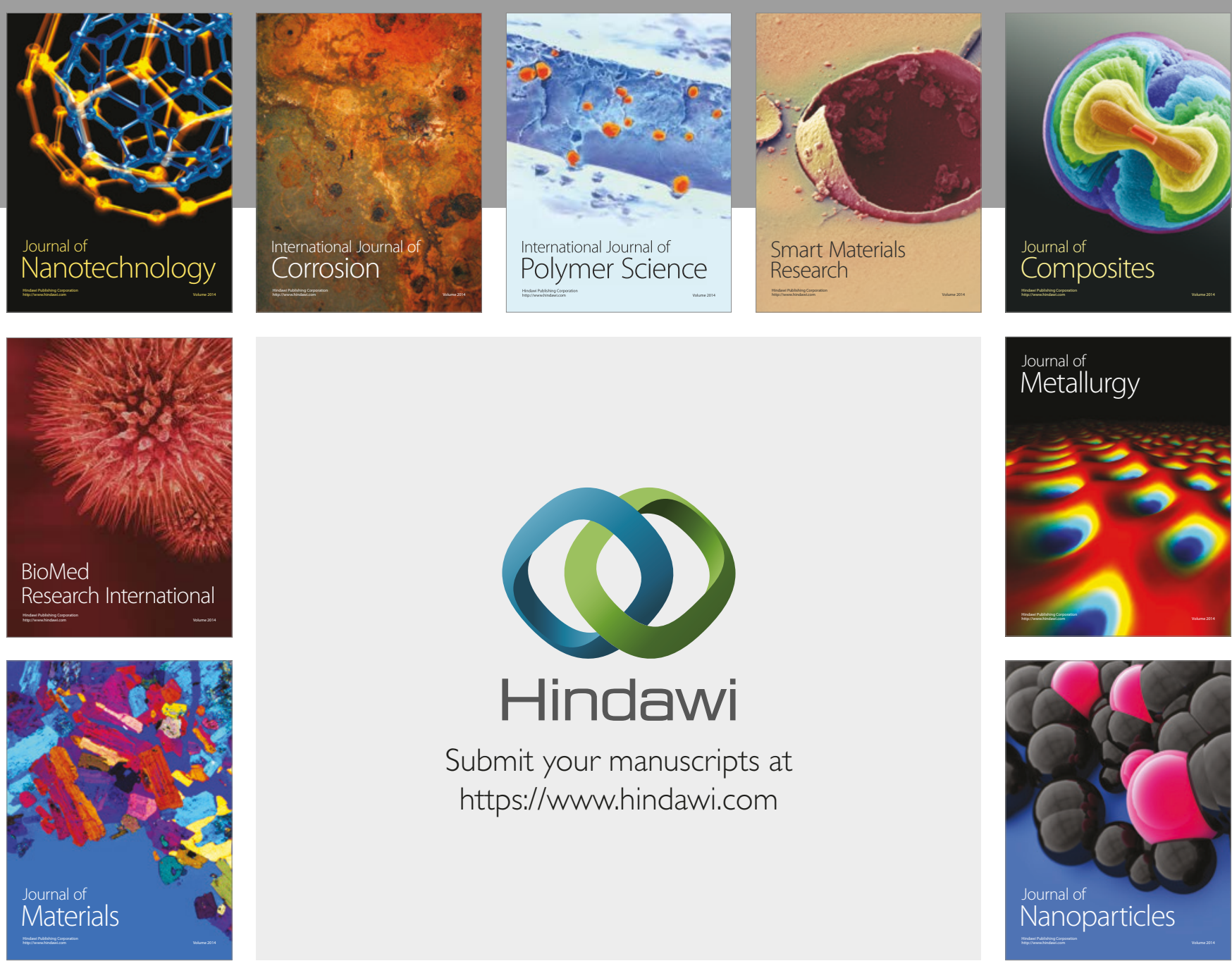

\section{Hindawi}

Submit your manuscripts at

https://www.hindawi.com
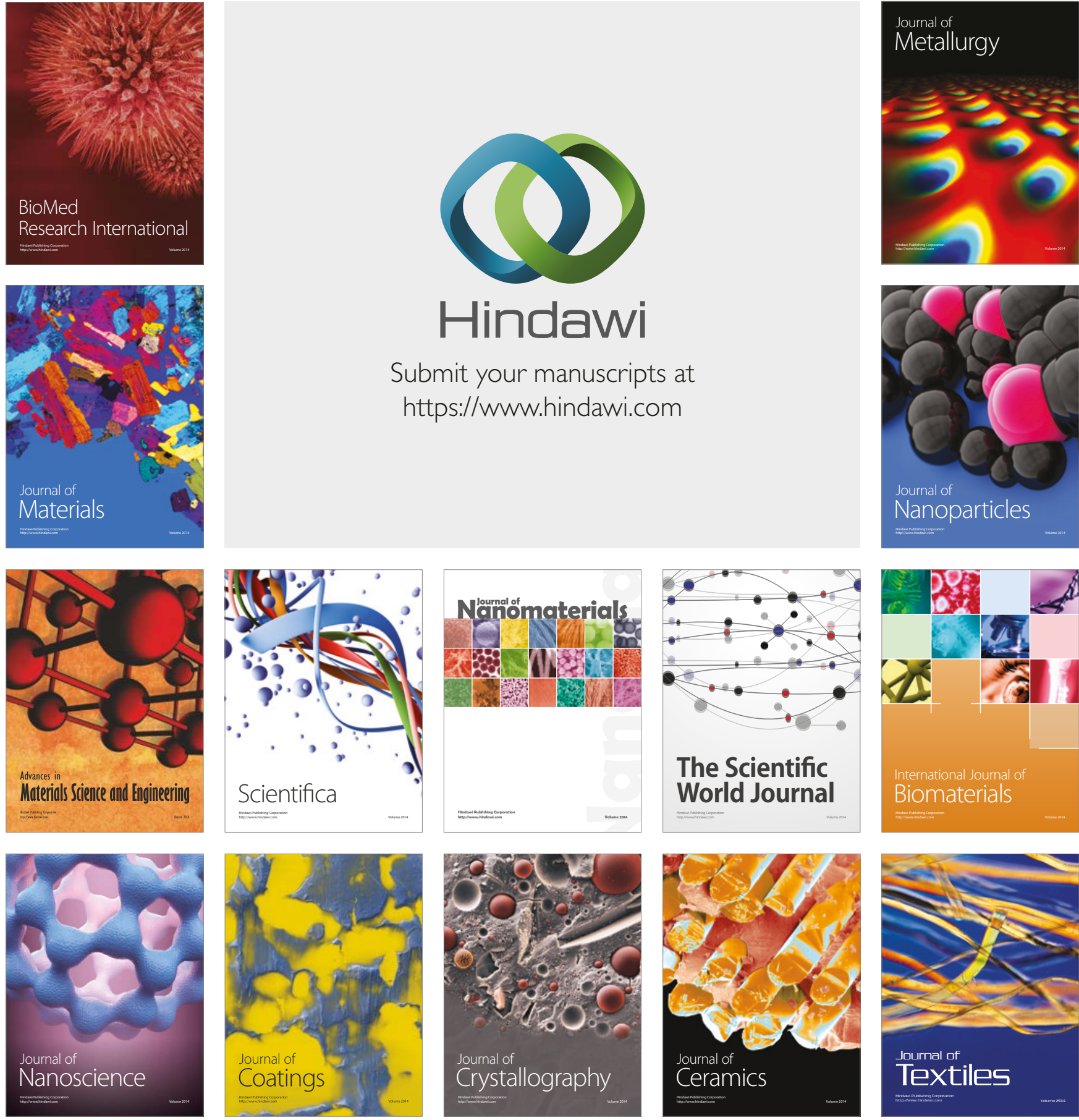

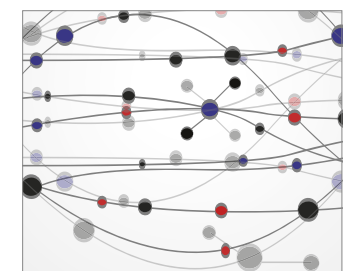

The Scientific World Journal
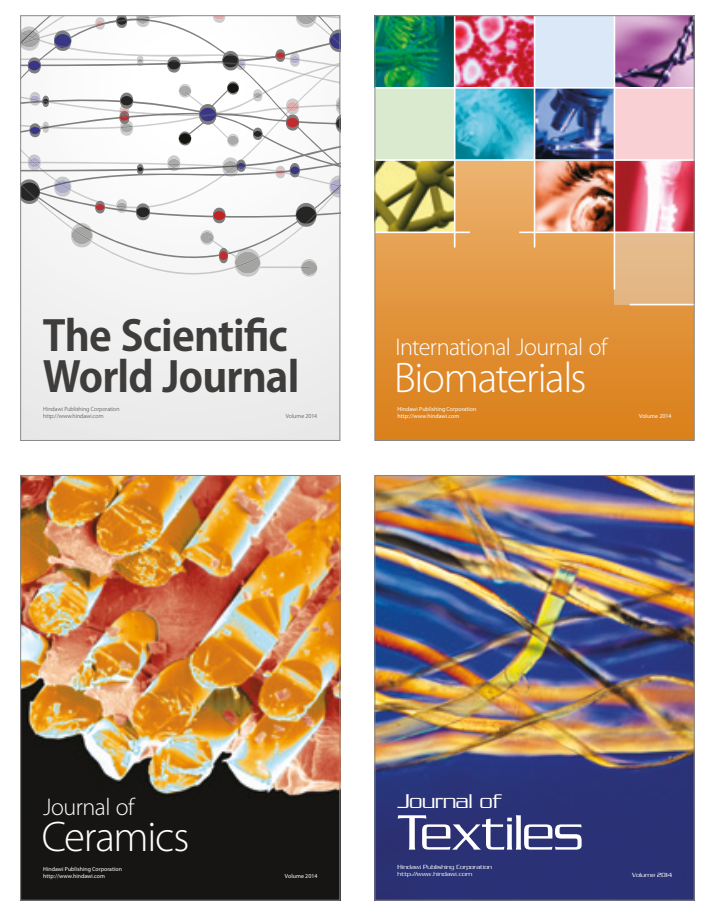